Journal of Systems Science and Information

Jun., 2021, Vol. 9, No. 3, pp. 321-334

DOI: $10.21078 /$ JSSI-2021-321-14

\title{
Blockchain or Not? Optimal Decisions for Food Retailers Considering Consumer Expertise
}

\author{
Linyuan HU \\ School of Economics and Management, Beijing Jiaotong University, Beijing 100044, China \\ E-mail: 19120577@bjtu.edu.cn \\ Jinzhi DING* \\ School of Economics and Management, Beijing Jiaotong University, Beijing 100044, China \\ E-mail: jzhding@bjtu.edu.cn \\ Xiying YANG \\ School of Economics and Management, Beijing Jiaotong University, Beijing 100044, China \\ E-mail: 19120592@bjtu.edu.cn
}

\begin{abstract}
This paper studies the benefit of the blockchain food traceability system (BFTS). Based on game theory and the willingness-to-pay model, pricing models are formulated considering important factors like the proportion of consumer with high expertise in traceability, risk attitude to doubtful traceability information and perceived convenience of traceability information checking. By compared the optimal total welfare under the BFTS and that under the traditional food traceability system in valuation analysis, conditions where applying the BFTS is more valuable than applying the TFTS are figured out. Finally, insightful management implications are given.
\end{abstract}

Keywords the blockchain food traceability system; consumer expertise; pricing; valuation analysis

\section{Introduction}

Under the outbreak of COVID-19 epidemic, food safety has become the focus of public attention. From June 11 to June 15, 2020, a total of 79 new cases were reported in Beijing, China. New cases of local COVID-19 infection and asymptomatic infections were continuously added, all of which came to Beijing's "Xinfadi" wholesale market of agricultural products. The event triggered public concerns about the safety of imported fresh foods. Experts said that the only thing to be thankful for in this emergency is that the food traceability system clarified the source and direction of the virus at the first time and won an opportunity to overcome the epidemic. Food traceability and detection not only plays a role in prevention and screening in this emergency, but also highlights the role of the food traceability system in ensuring food safety in the process of production and trade. There has existed the traditional food traceability system which has centralized system and list data structure. Information recorded in the traditional food traceability system challenged by the trust problem ${ }^{[1]}$, because only

Received June 30, 2020, accepted September 21, 2020

${ }^{*}$ Corresponding author 
one entity controls the database and the modification of data lacks transparency. This allows unfavorable data to be tampered with. A survey of 489 consumers from three major Australian cities revealed that trust in the food traceability system strongly predicts consumers' willingness to pay for traceable food. If consumers doubt the information on the food traceability system, they will distrust the quality of the product and refuse to pay for it.

The blockchain food traceability system (BFTS) features in audibility, immutability, and provenance $^{[2]}$. The BFTS mainly solves the trust problem and ensure the quality of the food product from the following three aspects. Firstly, information recorded in the BFTS is a set of time-stamped blocks that are linked by a cryptographic hash. The Merkel tree in the block can detect whether the data has been tampered with and trace back to the source of the tampered block. Secondly, under the decentralized network, the participants in the food supply chain will be involved in validating data through consensus mechanism. If one entity wants to justify the fake data, it needs to hack more than half of the nodes in the blockchain food traceability system. Besides, third-party regulators can be directly involved to issue the certification on the chain and exercise inspection. All transactions and rules are open and transparent to all participants. Thirdly, the authenticity of information is improved by harnessing IoT technology in the process of information entry. In sum, once traceability information is recorded on the chain, it hardly can be tampered with and deleted. If the traceability information reflects the quality problem of the food product, the related parties cannot deny their responsibility. Thus, the serious consequence promotes the all participants in the food supply chain to be self-discipline and ensure the quality of the food product. Hence, the BFTS is regarded as a trust creator and quality supervisor among the food supply chain ${ }^{[3,4]}$.

However, traceability information for consumers is a kind of surrogate quality cue ${ }^{[5]}$ that facilitates them to form their perceived quality for such a product. However, some consumers would like to directly observe color, aroma, shape and texture such intrinsic quality cues ${ }^{[5,6]}$ of food or comments from other consumers. The survey done by Jin and Zhou ${ }^{[7]}$ showed that $11.87 \%$ of the total 6243 respondents in Japan had used the beef traceability system and $5.48 \%$ of those had retrieved fresh produce traceability information. Although the BFTS can bring transparency of the food supply chain and be beneficial to consumers from the perspective of blockchain design purpose, this benefit may be lost from the perspective of retailers because retailers need to balance the cost and gain. Motivated by the above issue, this paper intends to study the conditions where applying the BFTS will benefit both consumers and retailers. To be specific, how can the advantages of applying the BFTS be achieved in an market with high-expertise consumers and low-expertise consumers.

The organization of the paper is as follows. Section 2 presents the related literature. Section 3 figures out conditions where the value of applying the BFTS is positive in a market with both high-expertise consumers and low expertise consumers. Section 4 valuation analysis is given. In Section 5, management implications and conclusions are given.

\section{Literature Review}

The food traceability system (FTS) combines law, procedures, process and technologies in order to ensure product safety and quality throughout the whole supply chain ${ }^{[8]}$. The FTS is not 
a novel topic (e.g., $[9,10])$. A trusted food traceability system decreases consumers' perceived uncertainty and strengthens their willingness to pay regarding fast food ${ }^{[11]}$. However, the traditional food traceability system (TFTS) has been faced with trust problems ${ }^{[12]}$. With the recent development of blockchain technology, more and more researchers are devoted to the application of the blockchain technology in FTS such as egg, fish, and so on ${ }^{[13-15]}$. Some papers ${ }^{[16-18]}$ theoretically illustrate the concept model for the blockchain food traceability system (BFTS) and related advantages. For example, Feng, et al. ${ }^{[19]}$ explained how the BFTS can realize the full information transparency and security and how the BFTS can be implemented in the food supply chain. The operational framework of blockchain-based traceability is clearly shown in his study. Shi and Choi ${ }^{[20]}$ analyzed the role of blockchain in providing visible and traceable food souring data and information and conclude it can improve food supply chain management finally. Although blockchain technology seems so suitable for supply chain traceability, trade-off between challenges and achievement needs much more analysis ${ }^{[17]}$. Yadav, et al. ${ }^{[21]}$ revealed significant adoption barriers of the blockchain technology in Indian food supply chain are "lack of government regulation and lack of trust among stakeholder to use blockchain".

When it comes to applying the FTS, consumer expertise is always considered. Consumer expertise is knowledge that consumers have acquired. Purchasing decision-making process and their actual behavior significantly vary according to consumer expertise ${ }^{[2-24]}$. Consumer expertise has been widely studied on wine traceability ${ }^{[25-27]}$ and traceability system ${ }^{[25]}$. Zhang, et al. ${ }^{[1]}$ suggested that the consumers without experience of using the traceability system are unwilling to pay for the product ensured by this system. And Yuan ${ }^{[28]}$ also found out that consumer expertise moderates perceived value of the food traceability system. Consumer expertise is discussed in research related to the food traceability systems, which means that this factor should be considered when study the value of the BFTS. Thus, high-expertise consumers (low-expertise consumers) are defined as consumers with (without) the habit to read and check traceability information when purchasing in this paper.

In addition, there are also studies on the value and role of the blockchain traceability technology for non-food products. For example, Choi ${ }^{[29]}$ studied the value of the blockchain authenticity and traceability technology for diamond selling. Choi defined the value of the blockchain authenticity and traceability technology as the differences of the optimal total profit of manufacture, the optimal total consumers surplus and the optimal total social welfare under a blockchain technology supported diamond selling platform and these under a traditional diamond selling network. Similar to but not the same as the definition used in Choi's study, this paper defines the value of the BFTS as the difference between the optimal total welfare from applying the BFTS and that from applying the TFTS. The optimal total welfare is defined as the sum of the optimal total retailer profit and the optimal total consumer surplus. This definition shows the main perspective of our study is the food retailer.

The related previous researches study the value and advantages of the BFTS mainly from the perspective of the design purpose. They do not provide a quantitative application strategy of the BFTS. The value of the BFTS have significant impact on the operation strategy of food supply chain, especially of retailers. Except cost, the proportion of high-expertise consumers, their risk attitude towards doubtful information and the convenience of traceability information 
checking all will influence pricing decision of retailers and then the value of the BFTS. Further analysis of their influence is needed. Therefore, this paper intends to study this to make up limitations of existing researches.

\section{Model Formulation Under the TFTS and the BFTS}

The value of the BFTS is defined as the difference between the optimal total welfare from applying the BFTS and that from applying the TFTS. The optimal total welfare is defined as the sum of the optimal total retailer profit and the optimal total consumer surplus. Therefore the pricing problems of retailers under two types of the food traceability system in a market with high-expertise consumers and low-expertise consumers should be studied at first.

\subsection{Problem Description}

The pricing problem description takes a certain food traceability system (FTS) as an example. A retailer $R$ should decides the price of his food product after applying the FTS. It is assumed that the retailer sells one type food at price $P$. He has a potential market size $M$. $I$ is the unit cost of applying the food traceability system. The total cost of the food traceability system is the sum of the fixed cost of the food traceability system and the total variable cost of the food traceability system. In order to establish a more direct link between the demand and the fixed cost, we define the unit fix cost $f$ is the fixed cost of the food traceability system divided by the total demand. The total variable cost is the variable cost multiplied by the total demand. The variable cost of the food traceability system is related to the cost of per proportion of credible traceability information $k$ and the proportion of credible traceability information $\beta$. For one-unit food product, if the food product has 20 entries of the traceability information, 10 of which can be verified, then the proportion of reliable traceability information is $\beta=50 \%$. The average cost of verifying each entry is 25 , then $k=\frac{20 * 25}{100 \%}=\frac{5}{1 \%}$. In sum, the unit cost of applying the food traceability is $I=k \beta+f$.

Besides, the convenience of traceability information checking $\alpha$ also should be considered. The convenience of traceability information checking $\alpha$ includes two parts. The first is accessing to traceability information. For example, in an online food shop, providing a hyperlink is more convenient than a QR code. What's more, the presentation of information should be related and intelligible. The second is checking the authenticity of traceability information. For instance, under the BFTS, data is recorded in chain structure and every verified entry has its own hash value to checking whether data has been tampered with.

The previous researches point out consumer expertise influences the value of applying the food traceability system. High-expertise consumers and low-expertise consumers are used to refer consumers with or without the habit to read and check traceability information when purchasing in this paper as mentioned before. They have different purchasing behavior which will be reflected in demand function. The demand function in this paper is based on the willingness-to-pay model (the WTP model) $d(p)=\Lambda \int_{v \geq p} f(v) \mathrm{d} v$ first proposed by Kalish in $1985^{[30]}$. Here $p$ represents the price of the product and $v$ is willingness-to-pay, a random variable with probability density function (p.d.f.) $f(v)$. The WTP model is applied in optimal pricing decision from the perspective of consumer purchasing behavior ${ }^{[31,32]}$. In area of blockchain technology and supply chain management study, Choi ${ }^{[29]}$ puts the factors consumer considering 
in diamond purchasing into the WTP model:

$$
d_{i}^{(R)}=n_{i} \int_{\left(p_{i}+\beta t+(1-\alpha) \gamma-s\right)}^{1} f\left(v_{i}\right) \mathrm{d} v_{i} .
$$

Different from Choi, this paper describes the factors that two types of consumers consider in food purchasing. The demand function will be explained in detail below.

Assumptions of the pricing problem are given as follows.

Assumptions 1 It is assumed that there is no competition.

Assumptions 2 It is assumed that the retailer sells one type food. Although there are more than one type of food products in reality, the average price and cost can be obtained to represent all.

Assumptions 3 It is assumed that the wholesale cost of the food product $c$ is fixed.

Assumptions 4 The probability density function of willingness-to-pay $f(v)_{i}(i=h, l)$ are assumed to have the 0-1 uniform distribution. The 0-1 uniform distribution is widely used by the previous related studies ${ }^{[29,32,33]}$.

All the notations used in the paper are summarized in Appendix Table A1.

\section{$3.2 \quad$ Pricing Model Under the TFTS}

Model TFTS describes the pricing problem when retailers use a traditional food traceability systems (TFTS). First is the demand function for Model TFTS. The demand function is derived from WTP model. Consumers have heterogeneous WTP $v_{i}(i=h, l)$, a random variable with p.d.f. $f(v)_{i}(i=h, l) . \quad f(v)_{i}(i=h, l)$ is a $0-1$ uniform distribution. For the highexpertise consumers, they will consider the harm of doubtful information $r(1-\beta)$. Their attitude to doubtful information is represented by $r$, which scales the perceived harm from doubtful information. If $1<r<\frac{\alpha^{\mathrm{TFTS}}-P^{\mathrm{TFTS}}}{1-\beta}$, consumers are risk aversion; if $r=1$, consumers are risk neutral. And they will also consider the convenience of traceability information checking $\alpha$. A high expertise consumer $m$ will buy if $P^{\text {TFTS }}+r(1-\beta)-\alpha^{\text {TFTS }} \leq v_{h m}$. For the lowexpertise consumers, they consider price $P^{\mathrm{TFTS}}$ and the quality $q$ perceived from the actual food product. Thus, a low expertise consumer $n$ will buy if $P^{\text {TFTS }}-q \leq v_{l n}$. The proportion of the high-expertise consumers are $\theta$. Then, the total number of consumers who will purchase the product from the retailer can be formulated as follows:

$$
D^{(\mathrm{TFTS})}=\theta M \int_{\left(P^{\mathrm{TFTS}}+r(1-\beta)-\alpha^{\mathrm{TFTS}}\right)}^{1} f(v)_{h} \mathrm{~d} v_{h}+(1-\theta) M \int_{\left(P^{\mathrm{TFTS}}-q\right)}^{1} f(v)_{l} \mathrm{~d} v_{l} .
$$

Then we can have the total net profit of the food retailer. It is calculated by multiplying profit per unit and the total realized demand then minus the fixed cost of applying the TFTS:

$$
\begin{aligned}
\mathrm{RP}^{(\mathrm{TFTS})}= & \left(P^{\mathrm{TFTS}}-c-I^{\mathrm{TFTS}}\right) M\left(\theta\left(1+\alpha^{\mathrm{TFTS}}-r(1-\beta)-P^{\mathrm{TFTS}}\right)\right. \\
& +(1-\theta)\left(1+q-P^{\mathrm{TFTS}}\right) .
\end{aligned}
$$

We derive that $\mathrm{RP}^{\text {(TFTS })}\left(P^{\mathrm{TFTS}}\right)$ is concave in $P^{\mathrm{TFTS}}$ for $\frac{\partial^{2} \mathrm{RP}^{(\mathrm{TFTS})}\left(P^{\mathrm{TFTS}}\right)}{\partial P^{2(\mathrm{TFTS})}}<0$, therefore the food retailer has the optimal price $P^{* \text { (TFTS })}$, is as follows.

$$
P^{*(\mathrm{TFTS})}=\frac{\left(X+c+I^{\mathrm{TFTS}}\right)}{2} .
$$


Then the optimal total net profit of the retailer, the optimal consumer surplus and the optimal total welfare under the TFTS are derived as follows.

$$
\begin{aligned}
\mathrm{RP}^{*(\mathrm{TFTS})}= & \frac{M\left(X-c-I^{\mathrm{TFTS}}\right)^{2}}{4}, \\
\mathrm{CS}^{*(\mathrm{TFTS})}= & M \theta \int_{\left(P^{\mathrm{TFTS}}+r(1-\beta)-\alpha^{\mathrm{TFTS}}\right)}^{1}\left[v_{h}-\left(P^{\mathrm{TFTS}}+r(1-\beta)-\alpha^{\mathrm{TFTS}}\right)\right] f\left(v_{h}\right) \mathrm{d} v_{h} \\
& +M(1-\theta) \int_{\left(P^{\mathrm{TFTS}}-q\right)}^{1}\left[v_{l}-\left(P^{\mathrm{TFTS}}-q\right)\right] f\left(v_{l}\right) \mathrm{d} v_{l} \\
= & \frac{M\left(X-c-I^{\mathrm{TFTS}}\right)^{2}}{8}, \\
\mathrm{TW}^{*(\mathrm{TFTS})}= & \mathrm{RP}^{*(\mathrm{TFTS})}+\mathrm{CS}^{*(\mathrm{TFTS})}=\frac{3 M\left(X-c-I^{\mathrm{TFTS}}\right)^{2}}{8},
\end{aligned}
$$

where $X=1+\theta\left(\alpha^{\text {TFTS }}-r(1-\beta)\right)+(1-\theta) q$. Here parameter $X$ is used to represent the factors consumers consider when purchasing under the TFTS.

We can have Lemma 3.1 which will be discussed with Lemma 3.2 below.

Lemma 3.1 In the Model TFTS, at the equilibrium, the retailer gets the optimal price: $P^{*(\mathrm{TFTS})}=\frac{\left(X+c+I^{\mathrm{TFTS}}\right)}{2}$, and the optimal total welfare $\mathrm{TW}^{*(\mathrm{TFTS})}=\frac{3 M\left(X-c-I^{\mathrm{TFTS}}\right)^{2}}{8}$, where $X=1+\theta\left(\alpha^{\text {TFTS }}-r(1-\beta)\right)+(1-\theta) q$.

Based on Lemma 3.1, we show the sensitivity analysis on the key factors influencing the optimal price and the optimal total welfare under the TFTS in Table 1.

Table 1 Sensitivity analysis for key factors under the TFTS

\begin{tabular}{ccccccc}
\hline & $M$ & $\theta$ & $r$ & $\beta$ & $\alpha^{\text {TFTS }}$ & $I^{\text {TFTS }}$ \\
\hline$P^{*(\mathrm{TFTS})}$ & - & $\uparrow$ & $\downarrow$ & $\uparrow$ & $\uparrow$ & $\uparrow$ \\
$\mathrm{TW}^{*(\mathrm{TFTS})}$ & - & $\uparrow$ & $\downarrow$ & $\uparrow$ & $\uparrow$ & $\downarrow$ \\
\hline
\end{tabular}

\subsection{Pricing Model Under the BFTS}

The value analysis of applying the BFTS is based on the optimal total welfare when applying the BFTS and the optimal total welfare when applying the TFTS which has been derived from Model TFTS. The effect of applying the BFTS is shown in purchasing decision of high-expertise consumers. They will trust the traceability information recorded in the BFTS. Therefore, in Model BFTS, the proportion of doubtful information can be regarded as zero. The demand function of Model BFTS is as follows:

$$
D^{(\mathrm{BFTS})}=\theta M \int_{\left(P_{\mathrm{BFTS}}-\alpha^{\mathrm{BFTS}}\right)}^{1} f(v)_{h} \mathrm{~d} v_{h}+(1-\theta) M \int_{\left(P^{\mathrm{BFTS}}-q\right)}^{1} f(v)_{l} \mathrm{~d} v_{l} .
$$

Then we can have the total net profit of the food retailer. It is calculated by multiplying profit per unit and the total realized demand then minus the fixed cost of applying the BFTS:

$$
\mathrm{RP}^{(\mathrm{BFTS})}=\left(P^{\mathrm{BFTS}}-c-I^{\mathrm{BFTS}}\right) M\left(\theta\left(1+\alpha^{\mathrm{BFTS}}-P^{\mathrm{BFTS}}\right)+(1-\theta)\left(1+q-P^{\mathrm{BFTS}}\right)\right) .
$$


We derive that $\mathrm{RP}^{(\mathrm{BFTS})}\left(P^{\mathrm{BFTS}}\right)$ is concave in $P$ for $\frac{\partial^{2} \mathrm{RP}^{(\mathrm{BFTS})}\left(P^{\mathrm{BFTS}}\right)}{\partial P^{2 \mathrm{BFTS}}}<0$, therefore the food retailer has the optimal price, is as follows:

$$
P^{*(\mathrm{BFTS})}=\frac{\left(Y+c+I^{\mathrm{BFTS}}\right)}{2} .
$$

Then the optimal total net profit of the retailer, the optimal consumer surplus and the optimal total welfare under the BFTS are derived as follows:

$$
\begin{aligned}
\mathrm{RP}^{*(\mathrm{BFTS})}= & \frac{M\left(Y-c-I^{\mathrm{BFTS}}\right)^{2}}{4}, \\
\mathrm{CS}^{*(\mathrm{BFTS})}= & M \theta \int_{\left(P^{\mathrm{BFTS}}-\alpha^{\mathrm{BFTS}}\right)}^{1}\left[v_{h}-\left(P^{\mathrm{BFTS}}-\alpha^{\mathrm{BFTS}}\right)\right] f\left(v_{h}\right) \mathrm{d} v_{h} \\
& +M(1-\theta) \int_{\left(P^{\mathrm{BFTS}}-q\right)}^{1}\left[v_{l}-\left(P^{\mathrm{BFTS}}-q\right)\right] f\left(v_{l}\right) \mathrm{d} v_{l} \\
= & \frac{M\left(Y-c-I^{\mathrm{BFTS}}\right)^{2}}{8}, \\
\mathrm{TW}^{*(\mathrm{BFTS})}= & \mathrm{RP}^{*(\mathrm{BFTS})}+\mathrm{CS}^{*(\mathrm{BFTS})}=\frac{3 M\left(Y-c-I^{\mathrm{BFTS}}\right)^{2}}{8},
\end{aligned}
$$

where $Y=1+\theta \alpha^{\text {BFTS }}+(1-\theta) q$. Here parameter $Y$ is used to represent the factors consumers consider when purchasing under the BFTS.

Lemma 3.2 In the Model BFTS, at the equilibrium, the retailer gets the optimal price: $P^{*(\mathrm{BFTS})}=\frac{\left(Y+c+I^{\mathrm{BFTS}}\right)}{2}$, and the optimal total welfare $\mathrm{TW}^{*(\mathrm{BFTS})}=\frac{3 M\left(Y-c-I^{\mathrm{BFTS}}\right)^{2}}{8}$ where $Y=1+\theta \alpha^{\mathrm{BFTS}}+(1-\theta) q$.

Based on Lemma 3.2, we show the sensitivity analysis on the key factors influencing the optimal price and the optimal total welfare under the BFTS in Table 2.

Table 2 Sensitivity analysis for key factors under the BFTS

\begin{tabular}{ccccc}
\hline & $M$ & $\theta$ & $\alpha^{\mathrm{BFTS}}$ & $I^{\mathrm{BFTS}}$ \\
\hline$P^{* \text { (BFTS) }}$ & - & $\uparrow$ & $\uparrow$ & $\uparrow$ \\
$\mathrm{TW}^{*(\mathrm{BFTS})}$ & - & $\uparrow$ & $\uparrow$ & $\downarrow$ \\
\hline
\end{tabular}

Lemma 3.1 and Lemma 3.2 show the factors that will influence the optimal price and the optimal total welfare under two types of the food traceability systems respectively. The sensitivity analysis shown in Tables 1 and 2 are as follows. The proportion of high-expertise consumers $\theta$ and the convenience of traceability information checking $\alpha$ are positively related to the optimal price level and the optimal total welfare. This implies that when other factors keep constant, the proportion of high-expertise consumers is high in the market or the food traceability system that is simple to operate and provides intelligible traceability information will bring higher profit margin. The proportion of credible traceability information $\beta$ provided by the BFTS is regarded close to 1 and therefore consumers risk attitude to harm of doubtful information $r(1-\beta)$ only exist in the TFTS. Risk aversion attitude and too much suspicious traceability information $(1-\beta)$ will decrease the optimal price and the optimal total welfare 
under the TFTS. The unit costs of applying two food traceability systems $I^{\text {BFTS }}$ and $I^{\text {TFTS }}$ will increase the optimal price but decrease the optimal total welfare. It implies if the cost of the BFTS is much higher than the cost of the TFTS, the most significant advantage, which is providing credible traceability information, of the BFTS will be weakened.

\section{Valuation Analysis of the BFTS}

\subsection{The Value of Applying the BFTS}

The optimal pricing strategies and the optimal total welfare under two types of the food traceability systems are derived. This section intends to figure out the value of the BFTS, abbreviated as VBC. As mentioned before, the value of the BFTS is defined as the difference between the total optimal total welfare from applying the BFTS and that from applying the TFTS.

$$
\begin{aligned}
\mathrm{VBC} & =\mathrm{TW}^{*(\mathrm{BFTS})}-\mathrm{TW}^{*(\mathrm{TFTS})} \\
& =\frac{3 M\left(Y-I^{\mathrm{BFTS}}+X-I^{\mathrm{TFTS}}\right)\left(Y-X-I^{\mathrm{BFTS}}+I^{\mathrm{TFTS}}\right)}{8},
\end{aligned}
$$

where $Y=1+\theta \alpha^{\mathrm{BFTS}}+(1-\theta) q, X=1+\theta\left(\alpha^{\mathrm{TFTS}}-r(1-\beta)\right)+(1-\theta) q$.

Theorem 4.1 (a) When only the optimal total welfare of the BFTS does not exist, the value of the BFTS is zero; (b) When only the optimal total welfare of the BFTS exist, the BFTS is definitely worthy applying; (c) When the optimal total welfare of two food traceability systems exist, if $\theta\left(\alpha^{\mathrm{BFTS}}-\alpha^{\mathrm{TFTS}}+r(1-\beta)\right)-\left(I^{\mathrm{BFTS}}-I^{\mathrm{TFTS}}\right)>0$, then the value of the BFTS is positive $\mathrm{VBC}>0$.

Theorem 4.1 distinguishes three conditions and shows the value of the BFTS under each condition. Factors that will influence the optimal total welfare still affect the value of the BFTS, which has been discussed above. Here we highlight the condition (c) where the optimal total welfare of two food traceability systems both exist.

For one thing, the difference between the unit cost of applying the BFTS and that of applying the TFTS ( $I^{\text {BFTS }}-I^{\text {TFTS }}$ ) hinders the value of the BFTS being positive. If retailers can achieve economies of scale after applying the BFTS, the difference can be inversed. More details will be discussed in the subsection below.

For another thing, the proportion of high-expertise consumers $\theta$ scales the advantages of the BFTS. The advantages of the BFTS mainly are the convenience of traceability information checking $\left(\alpha^{\mathrm{BFTS}}-\alpha^{\mathrm{TFTS}}\right)$ and providing credible information $r(1-\beta)$. The convenience of information checking includes two parts. The first is accessing to traceability information. The second is checking the authenticity of traceability information. Under the BFTS, data are recorded in chain structure and every verified entry has its own hash value. However, it is hard for consumers to check the authenticity of traceability information in the TFTS. Thus, if two systems are both easy to operate and access, the higher convenience of information checking under the BFTS, i.e., $\left(\alpha^{\text {BFTS }}-\alpha^{\text {TFTS }}\right)>0$ will bring higher value of the BFTS. Besides, if high-expertise consumers have risk aversion toward harm of doubtful traceability information, i.e., $r>1$ or the proportion of doubtful information $(1-\beta)$ in the TFTS is high, the value of applying the BFTS will increase. 


\subsection{The Cost of Per Proportion of Credible Traceability Information}

Since information is difficult to be modified once it is recorded on the blockchain, if a history of false information occurs, this will cause huge losses to the party providing false information. This design enables all parties that provide information to consciously regulate production and provide real data. In addition, the data is shared and jointly checked by all parties at the time of recording. Even if it should be backtracked again later, it can be done efficiently. For example, Wal-Mart's experiment to track mangoes shows that under the blockchain food traceability system it only takes 2.2 seconds while under the traditional food traceability system it takes about 7 days $^{1}$. This is mainly because under the traditional food traceability system, data is managed by each party, and more time and manpower are required to check and verify, which increases the cost of per proportion of credible traceability information $k$. Hence, the blockchain food traceability system can reduce the cost of per proportion of credible traceability information $k$. If the unit fix cost of applying the BFTS $f^{\text {BFTS }}$ is not so high than the unit fix cost of applying the TFTS, $f^{\text {TFTS }}$ the value of the BFTS is more likely to be positive. The unit fix cost of applying the BFTS is related to the demand of the traceable food. Therefore, in the next subsection, we will discuss the change of the proportion of high-expertise consumers $\theta$.

\subsection{The Proportion of High-Expertise Consumers}

The traditional food traceability systems are facing a serious trust crisis. Consumers who are unwilling to use traceability information are partly because they do not trust the traceability information or cannot verify the authenticity of the traceability information, so they do not rely on food traceability information to make purchase decisions. Actually, WalMart, one well-funded retail giant, has developed the BFTS supported by $\mathrm{IBM}^{[34]}$. This project is aimed at expanding sales by enhancing consumer confidence by providing trustworthy planting and processing details. Blockchain food traceability system (BFTS) has changed the way that only an entity manages traceability information into a way of multi-party participation, especially the direct participation of third-party regulatory agencies. For example, Chinese Academy of Inspection and Quarantine is one of participants in "Paobuji" blockchian traceability project designed by JD Chain ${ }^{2}$. The blockchain food traceability system (BFTS) uses smart contracts for automatic detection and encryption of entry, increasing the difficulty of information tampering and the cost of providing false information. Therefore, the BFTS can provide authentic and verifiable traceability information. This can attract some consumers who have given up using food traceability information because of trust problem. Applying the BFTS and related marketing promotion are possible to increase the proportion of high-expertise consumers in the market. When building the models, we assume that the proportion of high expertise in the market is constant. This assumption enables us to know the value of the BFTS under a relatively conservative valuation. However, in reality, the application of the blockchain food traceability system and related publicity and education may increase the proportion of high expertise in the market, which can reduce the fixed cost of applying blockchain technology, so

\footnotetext{
${ }^{1}$ https://thecounter.org/blockchain-food-traceability-walmart-ibm/.

${ }^{2}$ http://www.cbdio.com/image/site2/20190411/f4285315404f1e19523705.pdf.
} 
that food retailers can have more optimistic expectations of the value of the BFTS.

\section{Management Implications and Conclusions}

The COVID-19 epidemic in 2020 made it more important to adopt more reliable food traceability technology. COVID-19 infection incidents occurred in food companies in many countries including the United States, Canada, Britain and Germany since April 2020. In mid April, COVID-19 infection incidents started in Smithfield Foods, a pork processing factor in South Dakota, and became the largest single source outbreak of COVID-19 in the United States. It related to more than 640 new cases of COVID-19 infection. In June, China's "Xinfadi" agricultural products wholesale market became a new source of COVID-19 infection in Beijing. These events once again pointed out the importance of food traceability.

The giant international retailer, Wal-Mart, said that by the end of 2020, the overall traceable fresh meat will account for $50 \%$ of the total packaged fresh meat sales, and traceable vegetables Vegetables accounted for $40 \%$ of the total sales of packaged vegetables, and traceable seafood accounted for $12.5 \%$ of the total sales of seafood categories. In China, some head e-retailers have gradually promoted the application of the blockchain food traceability system, including Alibaba.com, JD.COM, Suning.com, etc.

Although it is a social appeal to replace the traditional food traceability system with a more credible food traceability system, for food retailers with limited financial strength, adopting or not adopting the blockchain food traceability system still needs a more detailed measurement of revenue and cost. Therefore, based on the above model and analysis, we will give the insightful management implication below.

\subsection{Management Implications}

Applying the BFTS has its advantages in providing credible traceability information. Compared with the TFTS, the cost of per proportion of credible traceability information of the BFTS are lower. However, if the fix cost of applying the BFTS is large, the price of the food product will increase while the total optimal welfare will decrease. The value of applying the BFTS is hardly to be positive. For instance, JD.COM, an online retailer, started the project "paobuji" that uses the BFTS to record growing and processing information of home-kept chicken which are sold two times the price of ordinary home-kept chicken ${ }^{3}$. And this project has only run for about one year as a public welfare project with the support of government funds.

However, the demand can dilute the fix cost and improve the value of the BFTS. This shows that food retailers should be able to achieve scale effect after applying the BFTS. This implies increasing demand is important. The food retailers who expect to update his TFTS or apply the BFTS first should know purchasing habit of his consumers. If there are high proportion of low-expertise consumers. Our findings show that the decision of applying BFTS should be more prudent. Because the low-expertise consumers do not rely on the food traceability system. Any type of traceability service is useless for them. If most of them have the habit to use the food traceability system when purchasing food products and they think the traceability information is not so credible in the TFTS. Applying the BFTS are more likely to increase the retailer

\footnotetext{
${ }^{3}$ https://blockchain.jd.com/?from=jrad_2276665\&loc $=2$.
} 
profits and consumer surplus, especially when consumers are sensitive to the risk that external quality information is fake.

Although, major social events like the fact that COVID-19 is transmitted through the food product, will increase the proportion of consumers concerned about food traceability information, retailers can also take actions to increase the proportion of consumers concerned about food traceability information, thereby expanding demand and increasing the price. There are some advice for the food retailers who want to achieve the positive value of applying the BFTS. They can increase the proportion of high-expertise consumers by educating low-expertise consumers to establish the habit of using food traceability information. The food retailers should inform his consumers the role of the blockchain technology in ensuring the authenticity of traceability information. They can try their best to improve the convenience of traceability information checking to attract the consumers who do not use the food traceability system because it is difficult to operate and unable to check the authenticity of the traceability information. First, the BFTS should be easy to operate and the information should be intelligible. Second, the guidance of how to checking the authenticity of traceability information in the BFTS should be given to consumers.

\subsection{Conclusions}

The blockchain technology is considered to subvert the tradition food traceability system (TFTS). The research question is motivated by the problem confronted by the food retailer. The problem is when the value of applying the BFTS is positive both for the consumers and the food retailer. This paper study the value of the BFTS based on the game theory and the willingnessto-pay model. First, we built two pricing models under the BFTS and under the TFTS in a market with high-expertise consumers and low-expertise consumers. And then we compare the optimal total welfare under the BFTS and that under the TFTS. Meaningful findings are acquired and highlighted as follows. The proportion of the high-expertise consumers, the proportion of doubtful traceability information under the TFTS, risk aversion attitude of highexpertise consumers, and the convenience of traceability information checking under the BFTS positively influence the value of applying the BFTS. The difference between the unit cost of applying the BFTS and that of applying the TFTS negatively affects the value of applying the BFTS. Food retailers should be able to achieve scale effect after applying the BFTS to dilute the fix cost of applying the BFTS when the fix cost of applying the BFTS is large.

Future research can explore the market where there is a competition between retailers and also can explore the incentives for retailers and suppliers to invest in the blockchain food traceability system under different revenue distribution strategies.

Acknowledgements We gratefully acknowledge the editor and two anonymous referees for their insightful comments and helpful suggestions that led to a marked improvement of the article.

\section{References}

[1] Zhang A R, Mankad A, Ariyawardana A. Establishing confidence in food safety: Is traceability a solution in consumers' eyes? Journal of Consumer Protection and Food Safety, 2020: 1-9. 
[2] Sachin S K, Angappa G, Rohit S. Modeling the blockchain enabled traceability in agriculture supply chain. International Journal of Information Management, 2020, 52: 101967.

[3] Yan Y, Liu X L, Hong K M, et al. Trustworthy traceability of quality and safety for pig supply chain based on blockchain. Springer. International Symposium on Artificial Intelligence and Robotics, 2018: 343-355.

[4] Schmidt C G, Wagner S M. Blockchain and supply chain relations: A transaction cost theory perspective. Journal of Purchasing and Supply Management, 2019, 25(4): 100552.

[5] Efthalia D, Dimitris S. Consumer evaluations of product certification, geographic association and traceability in Greece. European Journal of Marketing, 2003.

[6] Wang J, Yue H, Zhou Z. An improved traceability system for food quality assurance and evaluation based on fuzzy classification and neural network. Food Control, 2017, 79: 363-370.

[7] Jin S S, Zhou L. Consumer interest in information provided by food traceability systems in Japan. Food Quality and Preference, 2014, 36: 144-152.

[8] Angelo C, Maria Elena L, Marta M. Agriculture 4.0: How use traceability data to tell food product to the consumers. IEEE. 2020 9th International Conference on Industrial Technology and Management (ICITM), 2020: 197-201.

[9] Liao P A, Chang H H, Chang C Y. Why is the food traceability system unsuccessful in taiwan? Empirical evidence from a national survey of fruit and vegetable farmers. Food Policy, 2011, 36(5): 686-693.

[10] Techane B, BGirma G. Food traceability as an integral part of logistics management in food and agricultural supply chain. Food Control, 2013, 33(1): 32-48.

[11] Chen M F, Huang C H. The impacts of the food traceability system and consumer involvement on consumers' purchase intentions toward fast foods. Food Control, 2013, 33(2): 313-319.

[12] Giovanni M, Vittorio S. Blockchain and agricultural supply chains traceability: Research trends and future challenges. Procedia Manufacturing, 2020, 42: 414-421.

[13] Wang Z J, Wang T Y, Hu H, et al. Blockchain-based framework for improving supply chain traceability and information sharing in precast construction. Automation in Construction, 2020, 111: 103063.

[14] Daniel B, Arti M, Brett D, et al. A blockchain use case in food distribution: Do you know where your food has been? International Journal of Information Management, 2020, 52: 102008.

[15] Hang L, Israr U, Do-Hyeun K. A secure fish farm platform based on blockchain for agriculture data integrity. Computers and Electronics in Agriculture, 2020, 170: 105251.

[16] Risius M, Spohrer K. A blockchain research framework - What we (don’t) know, where we go from here, and how we will get there. Business and Information Systems Engineering, 2017, 59(6): 385-409.

[17] Susanne K, Massimo P. Technology assessment of blockchain-based technologies in the food supply chain. Journal of Cleaner Production, 2020, 269: 122193.

[18] Tian F. An agri-food supply chain traceability system for china based on RFID \& blockchain technology. IEEE in 2016 13th International Conference on Service Systems and Service Management (ICSSSM), 2016 : $1-6$.

[19] Feng H H, Wang X, Duan Y Q, et al. Applying blockchain technology to improve agri-food traceability: A review of development methods, benefits and challenges. Journal of Cleaner Production, 2020, 260: 121031.

[20] Shi X, Choi T M. Blockchain technologies for food supply chains: Information visibility and traceability. Technical report. Working Paper, The Hong Kong Polytechnic University, 2018.

[21] Yadav V S, Singh A R, Raut R D, et al. Blockchain technology adoption barriers in the indian agricultural supply chain: An integrated approach. Resources, Conservation and Recycling, 2020, 161: 104877.

[22] Durairaj M, Brian S, Zeynep G. Acquisition and impact of consumer expertise. Journal of Consumer Psychology, 1996, 5(2): 115-133.

[23] Christine M, Kristin D, David B, et al. Subjective knowledge, search locations, and consumer choice. Journal of Consumer Research, 2004, 31(3): 673-680.

[24] Vanitha S. The impact of recommendation agents on consumer evaluation and choice: The moderating role of category risk, product complexity, and consumer knowledge. Journal of Consumer Psychology, 2003, 13(1-2): 93-101.

[25] Fan Z P, Wu X Y, Cao B B. Considering the traceability awareness of consumers: Should the supply chain adopt the blockchain technology? Annals of Operations Research, 2020. 10.1007/s10479-020-03729-y.

[26] Even J L, Hanne K S. The roles of schema incongruity and expertise in consumers' wine judgment. Food Quality and Preference, 2019, 71: 261-269. 
[27] Carole H C, Sylvie C, Maud L D, et al. From perceptual to conceptual categorization of wines: What is the effect of expertise? Food Quality and Preference, 2020, 80: 103806.

[28] Yuan C L, Wang S M, Yu X L. The impact of food traceability system on consumer perceived value and purchase intention in China. Industrial Management \& Data Systems, 2020, 120(4): 810-824.

[29] Choi T M. Blockchain-technology-supported platforms for diamond authentication and certification in luxury supply chains. Transportation Research Part E: Logistics and Transportation Review, 2019, 128: $17-29$.

[30] Kalish S. A new product adoption model with price, advertising, and uncertainty. Management Science, 1985, 31(12): 1569-1585.

[31] Du S F, Wang L, Hu L. Omnichannel management with consumer disappointment aversion. International Journal of Production Economics, 2019, 215: 84-101.

[32] Huang J, Leng M, Parlar M. Demand functions in decision modeling: A comprehensive survey and research directions. Decision Sciences, 2013, 44(3): 557-609.

[33] Yao S Q, Zhu K J. Combating product label misconduct: The role of traceability and market inspection. European Journal of Operational Research, 2020, 282(2): 559-568.

[34] IBM Walmart. Tsinghua university explore the use of blockchain to help bring safer food to dinner tables across china, 2017.

[35] Bertrand J. Book review of theorie mathematique de la richesse sociale and of recherches sur les principles mathematiques de la theorie des richesses. Journal De Savants, 1883, 67: 499-508.

[36] Choi T M, Feng L P, Li R. Information disclosure structure in supply chains with rental service platforms in the blockchain technology era. International Journal of Production Economics, 2019, 221: 107473.

\section{Appendix}

Table A1 All notations used in the paper

\begin{tabular}{cl}
\hline Notation & Description \\
\hline Subscript & \\
$h$ & The low-expertise consumers \\
BFTS & The high-expertise consumers \\
TFTS & Traditional food traceability system \\
Parameter & \\
$M$ & The total number of potential consumers \\
$\theta$ & The proportion of the high-expertise consumers \\
$v_{i}$ & The willingness-to-pay of the high-expertise consumers $(i=h)$ \\
$f(v)_{i}$ & The low-expertise consumers $(i=l)$ \\
$\beta$ & The proportion of credible information \\
$\alpha$ & The convenience of traceability information checking \\
$r$ & The risk attitude of consumers toward doubtful information \\
$q$ & The quality perceived from the actual product \\
\hline
\end{tabular}




\begin{tabular}{cl}
\hline Notation & Description \\
\hline$c$ & The unit cost of a food product \\
$I$ & The unit cost of applying the food traceability system \\
$f$ & The unit fix cost of applying the food traceability system \\
$k$ & The cost of per proportion of credible traceability information \\
$X$ & The factors consumers consider when purchasing under the TFTS \\
$Y$ & The factors consumers consider when purchasing under the BFTS \\
$D$ & The actual demand \\
RP & Total net profit of a retailer \\
CS & Total consumer surplus \\
TW & Total welfare: The sum of total retailer profit and total consumer surplus \\
VBC & The value of a blockchian food traceability system \\
$P$ & \\
Decision Parameter & The price of the product \\
\hline
\end{tabular}

